\title{
Rhizosphere priming effect: A meta-analysis
}

\author{
Changfu Huo ${ }^{\text {a }}$, Yiqi Luo ${ }^{b}$, Weixin Cheng ${ }^{\text {a, }}{ }^{*}$
}

${ }^{a}$ Key Laboratory of Forest Ecology and Management, Institute of Applied Ecology, Chinese Academy of Sciences, Shenyang, 110016, China;

${ }^{\mathrm{b}}$ Department of Microbiology and Plant Biology, University of Oklahoma, Norman, OK 73019, USA;

${ }^{\mathrm{c}}$ Environmental Studies Department, University of California, Santa Cruz, CA 95064, USA.

* Correspondence author:

E-mail address: wxcheng@ucsc.edu (W. Cheng) 
Abstract: Rhizosphere priming is crucial for regulating soil carbon and nitrogen biogeochemical cycles. An appreciable number of studies have been conducted to quantify the rhizosphere priming effect (RPE), and have shown that the RPE is sensitive to changes of plant and soil conditions. These diverse results across individual studies offer us an opportunity to explore for potential general patterns and variability. In this study, we conducted a meta-analysis of RPE values taken from 31 publications. Our results showed that, on average, the RPE enhanced soil organic carbon mineralization rate by $59 \%$ across all studies. The magnitudes of the RPE significantly varied among plant types and soil texture. Within plant types, woody species showed the highest RPE followed by grasses while crops had the lowest level of the RPE, indicating that plant traits and physiology may exert important controls on the RPE. Soils with finer texture tended to produce stronger RPEs than soils with coarser texture, suggesting that interactions between the rhizosphere and the soil matrix may modulate the RPE. Furthermore, the level of the RPE is positively correlated with aboveground plant biomass, but surprisingly not with root biomass which is the commonly believed key variable for influencing the RPE. In addition, the RPE increased with the length of experimental duration, which implies that the RPE may persist much longer than previously believed because it impacts stabilized soil carbon more than labile carbon as the length of experimental duration increases. Overall, the results from this meta-analysis further illustrate several complex features of the RPE and call for future attentions to decipher this complexity.

Keywords: soil organic matter, soil carbon, soil respiration, plant-soil interaction, rhizosphere effect 


\section{Introduction}

Over the past decade, evidence indicates that rhizosphere processes play a crucial role in regulating soil carbon cycle (Finzi et al., 2015). The presence of live roots can suppress soil organic matter (SOM) decomposition rates by $50 \%$ or stimulate it by $380 \%$, when compared with soil incubations without plants (Cheng et al., 2014). This phenomenon is known as the rhizosphere priming effect (RPE). Hence, the magnitude of the RPE is similar to the effects of temperature and soil moisture on SOM decomposition (Zhu and Cheng, 2011). However, our current understanding on the RPE is still mostly based on scattered published results. A meta-analysis is needed to provide a quantitative assessment on the RPE.

The RPE is a change of SOM decomposition rate due to the presence of living roots and aboveground vegetation (Kuzyakov, 2002), while the general priming effect (PE) is a change of SOM decomposition rate due to substrate additions (Löhnis, 1926; Bingeman et al., 1953). The RPE is different from the general PE in several aspects. First, simple compounds such as glucose or amino acids are often used as the trigger substrates in studying the general PE, whereas, the commonly believed substrates causing the RPE are complex mixtures of root exudates and other rhizodeposits (Kuzyakov, 2010; Haichar et al., 2014). Second, in studies of the general PE, substrates are often added once at the beginning of the incubation (but see Qiao et al., 2014), while substrates are supplied continuously during plant growth in the case of the RPE. Third, the artificially created "hotspots" (i.e. locations) of the general PE are static, while the "hotspots" in the rhizosphere are moving through the soil matrix with root growth (Kuzyakov and Blagodatskaya, 2015). Fourth, and most importantly, the RPE occurs under a suite of physical, chemical, biological and environmental interactions between plants and soils (Cheng et al., 2014; Kuzyakov and Blagodatskaya, 2015), while the general PE is often observed as a much simpler response to substrate additions (Kuzyakov et al., 
2000). Because of these differences between the RPE and the general PE, and because meta-analyses of the general PE have recently been published (e.g. Zhang et al., 2013; Luo et al., 2016), this study strictly focuses on quantitative analysis of the RPE.

Reports published in the literature have indicated that different plant species produced different RPEs when grown in the same soil. For example, results from one study suggested that soybean (Glycine max) had a consistently stronger RPE than did wheat (Triticum aestivum) (Cheng et al., 2003). Some studies showed that grassland and crop species grown under the same condition resulted in very different magnitudes and directions of RPEs (Dijkstra et al., 2010; Shahzad et al., 2015; Wang et al., 2016). To date, however, no systematic synthesis has been done on the role of plant species in regulating the RPE. Furthermore, plant biomass (i.e. root, shoot and total) appears to have a positive linear correlation with the RPE for two plant species (Glycine max and Helianthus annuus) (Dijkstra et al., 2006; Zhu and Cheng, 2013). However, the generality of this correlation has not been tested broadly.

Significantly different levels of RPEs can also occur when the same plant species is grown in different soils (Dijkstra et al., 2006), but which soil properties lead to the differences in RPEs is unclear. Soils with high SOM content have been hypothesized to have the potential for producing higher RPEs because soils with more organic matter tend to also have more labile carbon (Kuzyakov, 2002). However, this hypothesis requires further testing as some soil incubation studies have shown that priming may actually accelerate the decomposition of both labile carbon and stabilized carbon (Fontaine et al., 2007). Some soils with lower N contents tend to have higher RPEs (Dijkstra and Cheng, 2007). But results from $\mathrm{N}$ fertilization experiments have indicated an inconsistent role of soil N status in regulating RPEs (Liljeroth et al., 1994; Cheng et al., 2003; Hoosbeek et al., 2006; Kumar et al., 2016). Other soil factors (e.g., soil moisture, temperature, $\mathrm{pH}$ value and physical characters) may also have the potential to influence the RPE, because, so far, all investigated soil variables appear to act on RPEs (Cheng et al., 2014). Therefore, sorting out potential patterns about the 
relationships between the RPE and soil variables requires a comprehensive analysis using all results available.

The temporal dimension of the RPE is another potentially important aspect that may need a comprehensive analysis. Many studies report values of the RPE based on one or two measurements in short-term experiments with durations from weeks to a few months (e.g. Thurgood et al., 2014; Wang et al., 2016). Some longer-term studies have shown multiple RPE values during an entire growing season (e.g. Cheng et al., 2003; Shahzad et al., 2015; Mwafulirwa et al., 2016). Only two studies have experimental durations longer than a year (Bader and Cheng, 2007; Dijkstra and Cheng, 2007). Thus, it remains unclear how the length of the experimental durations may influence the reported RPE values.

Meta-analysis as an objective and quantitative methodology has complementary advantages of subjective and qualitative reviews. General reviews or syntheses on the RPE have recently been published (Dijkstra et al., 2013; Cheng et al., 2014; Finzi et al., 2015). However, meta-analysis on the RPE is lacking. In order to address the above-mentioned issues, we carried out a meta-analysis on the RPE with the following key objectives: (1) to evaluate the overall mean level of the RPE reported so far, (2) to seek relationships between the RPE and other variables (e.g., plant biomass and soil properties), and (3) to identify the time scale of the RPE. Specifically, we addressed the following research questions: (1) Is the RPE positively correlated with plant biomass (shoots, roots, and total)? (2) Do different groups of plant species (e.g., crops, grassland species, and woody species) tend to produce different levels of the RPE? (3) What soil properties show significant correlations with the RPE? and (4) Does the RPE change as the experimental duration increases? 


\section{Materials and Methods}

\subsection{Data sources}

In this meta-analysis, we searched for relevant articles in Web of Science database (publication years 1900-2016) using the "Advanced Search" feature and two search statements: (1) TS = rhizosphere AND TS = priming; and (2) TS = rhizosphere AND TS = decomposition AND TS = isotope ("TS", one of the "Field Tags" in the search engine, stands for "Topic"). A total of 232 articles were found by using the first search statement and 72 articles were found by using the second search statement. All found articles were further screened, and articles do not satisfy the following criteria were excluded from further analysis: (1) the article reports SOM-derived $\mathrm{CO}_{2}$ release rate(s) separately from root-derived $\mathrm{CO}_{2}$ (which includes rhizosphere microbial respiration utilizing rhizodeposits) using a ${ }^{13} \mathrm{C}$ or ${ }^{14} \mathrm{C}$ isotope technique; and (2) the study includes unplanted soil controls under the same environmental conditions as the planted treatments. Both criteria are required for quantitative determination of the RPE. Studies under wetland settings were also excluded (e.g. Wolf et al., 2007; Linkosalmi et al., 2015; Mueller et al., 2016), because of the drastically different soil water conditions. After these restrictions, a total of 191 quantitative measurements of the RPE from 31 published articles were identified as suitable for further analysis (Table S1).

For each study, we tabulated information on soil organic matter decomposition rates of both planted soils and unplanted soil controls (i.e. SOM-derived $\mathrm{CO}_{2}$ efflux rates), their associated standard deviation and the sample size. We also collected other frequently reported information, including experimental settings, plant species, plant biomass, soil texture, soil organic carbon and nitrogen contents, $\mathrm{pH}$, and microbial biomass (Table S2). Most of the RPE values were determined under controlled environmental conditions, so soil moisture, soil temperature and lighting intensity at the time of RPE measurements were not tabulate for further analyzing. When data were presented in figures in original publications, they were extracted by GetData (V2.20) software. In addition, we 
unified units among studies prior to statistical analysis.

Furthermore, for categorical variables, plant species were grouped into woody species, grassland species, crops and others; soil types were grouped according to soil texture: fine (clay loam, silty loam and loam) and coarse (sandy loam and loamy sand).

\subsection{Statistical analysis}

\subsubsection{Average Effect Size of the RPE under plant and soil groups}

We carried out meta-analysis using MetaWin software (Rosenberg et al., 2000) to assess the overall magnitude of the RPE as reported in the published literature and the relationship between the degree of the RPE and the associated categorical variables of plant groups and soil texture groups. Among the 191 data points of the RPE collected from 31 articles, some data points came from measurements at deferent time points (i.e. repeated measures) under the same treatment (e.g. plant species or soil type) in a particular experiment. As required by meta-analysis procedure (removal of time-dependency), we aggregated the data points from repeated measures using the following equation (Liao et al., 2008):

$\mathrm{M}=\sum_{\mathrm{i}=1}^{\mathrm{j}} \frac{\mathrm{Mi}}{\mathrm{j}}, \quad \mathrm{SD}=\sqrt{\frac{\sum_{\mathrm{i}=1}^{\mathrm{j}} \mathrm{SD}_{\mathrm{i}}^{2}\left(\mathrm{n}_{\mathrm{i}}-1\right) \mathrm{n}_{\mathrm{i}}}{\left(\sum_{\mathrm{i}=1}^{\mathrm{j}} \mathrm{n}_{\mathrm{i}}-1\right) \sum_{\mathrm{i}=1}^{\mathrm{j}} \mathrm{n}_{\mathrm{i}}}}$

Where $M$ is the overall aggregated mean for the particular treatment and $S D$ is the associated standard deviation for $M ; j$ is the number of repeated measures under one treatment $(\geq 2), M_{i}, S D_{i}$ and $n_{i}$ are mean, standard deviation and sample size on the $i$ th sampling times, respectively. The aggregation of repeated measures was done on the SOM decomposition rates of both the planted soil and the unplanted soil. After the aggregation of repeated measures and removal of a few outliers, the original 191 data points were reduced to 74 data points. These 74 data points were used for this part of the meta-analysis (Table S2).

For each of these 74 data point, we tabulated the means of SOM decomposition rates (as 
determined by SOM-derived $\mathrm{CO}_{2}$ efflux rate) for the planted soil and the unplanted soil control, and their associated standard deviation and sample size. Percent priming effect was calculated by using this equation: $\mathrm{RPE} \%=\left(\mathrm{R}_{\text {planted }}-\mathrm{R}_{\text {unplanted }}\right) / \mathrm{R}_{\text {unplanted }} \mathrm{X} 100$; where $\mathrm{R}_{\text {planted }}$ is the SOM decomposition rate of the planted soil and $\mathrm{R}_{\text {unplanted }}$ is the SOM decomposition rate of the unplanted soil.

Effect size for each data point was calculated as the natural log of the response ratio (RR) (Gurevitch et al., 2001): $\ln (\mathrm{RR})=\ln \left(\frac{X_{t}}{X_{c}}\right)$

where $X_{t}$ and $X_{c}$ are the means of SOM derived $\mathrm{CO}_{2}$ efflux rate of the planted soil and the unplanted control, respectively. The log transformation was done to improve the statistical behavior. The variance $\left(v_{\operatorname{lnR}}\right)$ associated with each effect size was calculated by using the following equation (Hedges et al., 1999):

$v_{\operatorname{lnR}}=\frac{S D_{t}^{2}}{n_{t} X_{t}^{2}}+\frac{S D_{c}^{2}}{n_{c} X_{C}^{2}}$

where $\mathrm{SD}_{\mathrm{t}}$ and $\mathrm{SD}_{\mathrm{c}}$ are the standard deviations for the planted soil and the unplanted soil control, respectively; $\mathrm{n}_{\mathrm{t}}$ and $\mathrm{n}_{\mathrm{c}}$ are the sample sizes for the planted soil and the unplanted soil control, respectively. $\mathrm{A} \ln (\mathrm{RR})=0$ indicates no rhizosphere priming effect, $\ln (\mathrm{RR})>0$ means positive priming effect, and $\ln (\mathrm{RR})<0$ represents negative priming effect.

We calculated the $95 \%$ confidence intervals (CI) for the overall means of all 74 effect sizes, and for the average effect size within each plant type groups and soil texture groups by varianceweighted bootstrapping (999 iterations) using MetaWin software (Rosenberg et al., 2000). If 95\% CI did not overlap with 0 , it indicated a significant RPE. If the 95\% CI of a particular group (e. g., plant type or soil texture) did not overlap with the CI of another group, the two groups are significantly different from each other.

\subsubsection{Influence of Numerical Variables on the RPE}

Along with the 191 data points of the RPE (also represented as response ratio or effect size), we also collected plant aboveground biomass (113 data points), root biomass (113 data points), total 
plant biomass (113 data points), Days After Planting (DAP) (190 data points), soil C \& N contents and $\mathrm{C}: \mathrm{N}$ ratio (53 data points), $\mathrm{pH}$ values ( 65 data points), and soil microbial biomass $\mathrm{C}$ (39 points) from the 31 published articles.

We noted two major issues with these data. First, mismatched data points among these variables were common. For example, many DAP data points are associated with repeated measures of the RPE and do not correspond to other variables, so they are highly mismatched. Second, missing data are widespread, as apparently indicated by the very different number of data points for different variables. Because of these issues, multi-variate step-wise analysis could not and should not be applied to these data. It was also likely because of these issues that step-wise regression analysis was rarely part of any publication using meta-analysis.

In order to better use these data, we employed two approaches for analyzing the relationships between the values of the RPE [as represented by effect sizes, i.e. $\ln (\mathrm{RR})$ ] and several numerical variables including plant aboveground biomass, root biomass, total plant biomass, experimental duration (i.e. DAP: days after planting), soil carbon content, soil nitrogen content, soil C:N ratio, soil $\mathrm{pH}$, and soil microbial biomass carbon. In our first approach, we employed a continuous random effect model of MetaWin software (Rosenberg et al., 2000) to analyze these relationships between effect sizes of the RPE [ln (RR)] and the numerical variables mentioned above. This approach calculated total heterogeneity in effective sizes $\left(\mathrm{Q}_{\mathrm{T}}\right)$, the heterogeneity in effect sizes associated with each variable $\left(\mathrm{Q}_{\mathrm{M}}\right)$, and the residual error $\left(\mathrm{Q}_{\mathrm{E}}\right)$. The $\mathrm{Q}$ statistic approximately follows a chi-square distribution, which allows a statistical test of the null hypothesis that all effect sizes are equal. The results of this approach were given in Table 1. Our second approach was to use simple linear correlation analyses between values of the RPE and each of the above mentioned continuous variables using SPSS software (2001, ver. 13.0; SPSS Inc., Cary, NC). The results of the second approach were combined with that from the first approach (Table 1). 


\section{Results}

\subsection{Rhizosphere priming across plant and soil types}

Across studies, the SOM decomposition rate under the planted treatment was abundantly higher than that of the unplanted treatment when both were measured under similar soil temperature and moisture conditions, as shown by the overall average value ( 0.47 with $95 \%$ CI from 0.37 to 0.56$)$ of the effect size of the RPE (Fig. 1). This average effect size indicated a response ratio of 1.59 or 1.59 times stimulation of SOM decomposition rate by the RPE as compared to the average rate of the unplanted control. The $95 \% \mathrm{CI}$ of $0.37-0.56$ in effect sizes could be translated to $95 \% \mathrm{CI}$ of $1.45-$ 1.75 in response ratios, or $95 \%$ probability that the average stimulation of SOM decomposition rates by the RPE falls within the range of 1.45 to 1.75 times of the unplanted control rate. The results from this meta-analysis also indicated a trend that the average effect sizes of the RPE for plant groups of woody species, grassland species, and crops were different from each other. The mean effect size of woody species, grassland species and crops were 0.77 (95\% CI: 0.60- 0.93), 0.57 (95\% CI: 0.38 $0.75)$ and 0.38 (95\% CI: $0.25-0.51)$, respectively. Woody species tended to produce statistically higher $(P<0.05)$ RPEs than crops $(2.16$ vs. 1.46 times stimulation of SOM decomposition rate by the RPE), while grassland species produced intermediate RPEs with a confidence interval overlapping with the other two groups. Furthermore, the effect size of the RPE significantly $(P<$ 0.05) depended on soil texture. The average effect sizes of the RPE for fine and coarse texture soil groups were 0.62 (95\% CI from 0.46 to 0.75$)$ and 0.35 (95\% CI from 0.22 to 0.47$)$, respectively (Fig.

1). This result indicated that soils with finer texture tended to produce higher RPEs than that of coarser texture, or 1.86 vs. 1.42 times stimulation of SOM decomposition rates by the RPE for the fine texture group vs. the coarse texture group. 


\subsection{Dependence of the RPE upon plant and soil variables}

We analyzed the relationships between values of the RPE [as represented by effect sizes, i.e. $\ln$ (RR) ] and each of the following numerical variables: (1) plant aboveground biomass (113 data points), (2) root biomass (113 data points), (3) total plant biomass (113 data points), (4) experimental duration (i.e., DAP: days after planting) (190 data points), (5) soil carbon content (53 data points), (6) soil nitrogen content (53 data points), (7) soil C:N ratio (53 data points), (8) soil $\mathrm{pH}$ (65 data points), and (9) soil microbial biomass carbon (39 data points). Two statistical approaches were applied: (1) continuous random effect model of MetaWin software (Rosenberg et al., 2000), and (2) simple linear correlation analysis of SPSS software (SPSS Inc., Cary, NC). Results of these analyses using both approaches indicated that there were significant relationships between the effect size and total plant biomass, aboveground biomass, days after planting and soil microbial biomass (Table 1, Fig. 2). Whereas, root biomass, soil carbon content, soil nitrogen content, soil C:N ratio, and $\mathrm{pH}$ value showed no significant relationships with the effect sizes (Table 1). The analysis of Continuous Random Effect did not rest on any assumption about the kind of the relationships (e.g., linear or nonlinear), but only assessed the level of impact by an independent variable on the dependent variable (i.e., the effect size of the RPE). The fact that the results from both approaches corroborated signaled that the linear assumption used in the analysis of linear correlations was not an important issue, even though most independent variables accounted for relatively low level of the total variability of the effect sizes.

Interestingly, the correlation between the RPE and plant shoot biomass, but not root biomass, was statistically significant and accounted for $11.9 \%$ of the total variation of the $\mathrm{RPE}\left(\mathrm{R}^{2}=0.119\right)$ (Table 1, Fig. 2), given that roots would normally be expected to have a more direct connection with the RPE. Another independent variable, soil microbial biomass carbon was also positively correlated 
with the level of the RPE (Table 1, Fig. 2). However, three outliers from two articles (Sinyakina and Kuzyakov 2002; Shahzad et al., 2012) were excluded from the analysis. If the three outliers were included, the correlation between the RPE and soil microbial biomass became insignificant. More noteworthy was that the correlation between the RPE and DAP (days after planting, a measure of experimental duration) was highly significant and accounted for $22.8 \%$ of the total variation of the RPE $\left(\mathrm{R}^{2}=0.228\right)$ (Table 1, Fig.2). We noted that the six data points with the longest DAP (395 days) from one study (Dijkstra and Cheng, 2007) might have particularly high impact on the relationship. We re-analyzed the data after excluding the six data points, and found that the regression was still highly significant $\left(P<0.001, R^{2}=0.172\right)$. This suggested that the positive correlation between the level of the RPE and DAP was quite robust.

\section{Discussions}

\subsection{General pattern of the RPE}

Our meta-analysis showed that the RPE, on average, stimulated soil organic carbon decomposition by $59 \%$ above the rate of unplanted soil controls (Fig. 1). This average value was derived from a data set of 74 data points from 31 published studies. It should be noted that 41 of the 74 data points were collected from experiments using crops, and that only 11 of the 74 data points were from woody species. Therefore, this overall average value may bear more relevance to agricultural systems (or grasslands, 16 of the 74) than forests. Nevertheless, this broad-based average value of the RPE has not been presented previously. Based on individual observations in the entire data set, rhizosphere priming may inhibit SOM decomposition by 79\% (Thurgood et al., 2014), or stimulate SOM decomposition by more than 500\% (Dijkstra and Cheng, 2007; Shahzad et al., 2015;) when compared with soil incubations without plants. Given this wide range of the RPE reported in individual studies, the $95 \%$ confidence interval of $45 \%$ to $75 \%$ RPE values associated with the 
overall mean of 59\% RPE in this meta-analysis is quite narrower than expected. Therefore, this overall average value of 59\% RPE from the meta-analysis, together with the wide range of values reported from individual studies, helps us to more realistically gauge the overall potential and significance of the RPE in regulating biogeochemical cycles in terrestrial ecosystems (Finzi et al., 2015). Furthermore, two recent studies using meta-analysis have reported that the "general" priming effect produced from addition of isotope labeled substrates may accelerate native SOM decomposition by $14.2 \%$ (Luo et al., 2015) or $26.5 \%$ (Zhang et al., 2013) on average. In comparison, the overall average value of 59\% RPE from our current meta-analysis is at least two times higher than their values. This gap may reflect the fundamental difference between the RPE and the "general" priming effect as described in the introduction. This level of difference between the RPE and the priming effect of added substrates is reasonable because rhizosphere activities are commonly recognized as one of the most crucial 'hot spots' and the pivotal force behind 'hot moments' in soil systems (Kuzyakov and Blagodatskaya, 2015).

\subsection{Temporal scales of the RPE}

Temporal aspects of the RPE are crucial for understanding SOM decomposition. The current meta-analysis provided a new line of evidence supporting the idea of long lasting RPEs. Experimental duration (Days after planting) was the most influential variable for controlling the RPE among a total of 9 variables considered (Table 1, Fig. 2), and accounted for $22.8 \%$ of the total variation of the RPE in the statistical analysis. Furthermore, the level of the RPE significantly increased as the experimental duration increased (Fig. 2), which indicated that the RPE impacted the decomposition of stabilized SOM more than the labile SOM after the relatively labile SOM was largely exhausted as the experimental duration went longer. As widely known, the decomposition of labile SOM largely dominates at the beginning of an experiment and diminish at later stage. 
Therefore, the RPE in the short-term (days to weeks) is generally believed to be mostly relevant to the dynamic change of labile SOM which is a small fraction of the total SOM in most soils, whereas the RPE in the longer-term (months to decades) may influence stabilized SOM (the dominant form of SOM) (Rousk et al., 2015). Indeed, some other evidence also indicates that the RPE is a long-term phenomenon. A greenhouse experiment involving two tree species has shown that the RPE persisted at a high level throughout the entire experimental duration of 395 days (Dijkstra and Cheng, 2007). Moreover, stabilized SOM including black carbon can be primed by adding external labile substrates (Fontaine et al., 2007; Kuzyakov et al., 2009; Bernal et al., 2016; Vestergärd et al., 2016). Results from FACE (Free-Air $\mathrm{CO}_{2}$ Enrichment) experiments also imply the continuous nature of the enhanced RPE under the elevated $\mathrm{CO}_{2}$ treatment (Drake et al., 2011; Phillips et al., 2012, Van Groenigen et al., 2014). Results from a study of the RPE on ${ }^{13} \mathrm{C}$-labelled litter decomposition also suggest that the RPE tended to associated with shifts in microbial composition in a relatively long-term timeframe (Bird et al., 2011). Overall, some available evidence so far indicates that the RPE is likely to persist beyond months and years in perennial-dominated ecosystems.

\subsection{Driving variables of the RPE}

Concerning what variables drive the RPE, several new patterns emerged from our meta-analysis. First, the magnitude of the RPE was significantly different among broad plant types, woody species showing the highest RPE, followed by grassland species, and crops with the lowest level of the RPE (Fig. 1). It should be note that, due to the relatively low number of data points for woody species in the current data set, caution is warranted. Given that the current data set is heavily dominated by crops, the overall average value of the RPE could be much higher if more data were from woody species or grassland species. Human selection processes through domestication and crop breeding 
may be responsible for the lower RPE of crops, because these processes tend to select for grain production in relatively fertile fields at the cost of lowering belowground input, thereby reducing the RPE. At the presence, what plant traits are linked to the RPE remains an open research question. Theoretically the RPE can be controlled by root exudation, root litter input, root architecture and mycorrhizal fungi. A study with 12 tree species showed that rhizosphere effects on soil microbes and their activities were significantly higher for ectomycorrhizal (ECM) species than for arbuscular mycorrhizal (AM) species (Phillips and Fahey, 2006), which indicated that ectomycorrhizal roots likely induce higher RPEs (Brzostek et al., 2015). Another study using grassland plants showed that root exudation played a much bigger role in regulating the RPE than root litter input or mycorrhizal fungi (Shahzad et al., 2015). Furthermore, the quality and quantity of labile $\mathrm{C}$ input might determine the direction and magnitude of the RPE (Wang et al., 2015; Liu et al., 2017). Overall, the relative differences in the RPE among different plant species are intriguing and warrant more research in the future.

The second new feature that emerged from our current meta-analysis was that plant shoot biomass showed stronger connection with the RPE, not the commonly-believed root biomass. Statistical analysis of 113 data points in the current data set showed that the level of the RPE was positively and linearly correlated with plant shoot biomass across all plant types $(P<0.001)$ (Table 1); and the correlation accounted for $11.9 \%$ total variation of the RPE $\left(\mathrm{R}^{2}=0.119\right)$ (Fig. 2). In contrast, root biomass showed no correlation with the RPE and accounted for nearly zero variation. This new feature clearly suggests that plant activities aboveground are intimately connected with the rhizosphere activities which ultimately drive the RPE. Furthermore, this new result also implies that other root attributes such as root exudates, mycorrhizal type and rhizodeposition, rather than root biomass per se may largely modulate the RPE (Shahzad et al., 2015). Although the close connection between photosynthetic activity and the RPE was previously reported in individual studies 
(Kuzyakov and Cheng, 2001; 2004), this result from our meta-analysis adds a level of generality to this realization.

The third new point of our current meta-analysis is that soil texture influences the level of the RPE; soils with a finer texture tended to produce a higher level of the RPE than soils with a coarser texture (Fig. 1). To our best knowledge, this is the first time this phenomenon has been reported for the RPE. The potential influence of soil properties on the RPE has rarely been treated as a focal topic of investigation in published studies (Dijkstra et al., 2006; Keith et al., 2015). Soil texture as a key soil property is apparently connected with physical capability for protection and stabilization of SOM mainly by affecting soil aggregation and mineral adsorption of SOM (Thurgood et al., 2014; Creamer et al., 2016). Based on a recent finding that a common root exudate, oxalic acid, stimulated SOM loss by liberating mineral-protected organic compounds (Keiluweit et al., 2015), it is reasonable to believe that the interaction between rhizosphere activities and soil chemical-physical matrix is a major aspect of the RPE, which requires serious attentions for future research.

Lastly and more importantly, the generally weak accounts of the RPE by all variables considered here in the present meta-analysis pointed to the complex nature of the RPE. Experimental duration (or days after planting) was the most influential variable in this data set, which accounted for $22.8 \%$ of the overall variation of the RPE (Fig. 2). The second most influential variable was aboveground plant biomass which accounted for $11.9 \%$ of the overall variation of the RPE. The rest of the variables individually accounted for less than $20 \%$ of the overall RPE variation. We consider this result as a composite indication that past research on the RPE have not grasped the 'right' variables, or that the RPE stems from nexus-type controls by multiple variables. On one hand, if the RPE is intimately connected with multiple variables and their interactions in consort, there will be little hope to enhance our understanding on the question of what controls the RPE by testing individual 
mechanistic hypotheses in isolation. On the other hand, the recent conceptual framework of "hot spots" and "hot moments" (Kuzyakov and Blagodatskaya, 2015) indeed emphasizes the importance of understanding dynamic features associated with rhizosphere processes and microbial metabolic parameters such as turnover rates and substrate utilization. Some studies have illustrated the potential importance of microbial turnover for critically modulating the RPE (Herman et al., 2006; Cheng, 2009; Kuzyakov and Xu, 2013). Fortunately, recent progress in method development for measuring microbial turnover and substrate utilization using ${ }^{18}$ O-labeling (Spohn et al., 2016a; 2016b) may overcome the widely known methodological difficulties in this area of research, and pave the road for better grasping crucial variables for regulating the RPE in the near future.

\section{Acknowledgements}

We thank four anonymous reviewers for their valuable comments on the early version of this manuscript. This work was supported by the Strategic Priority Research Program (B) of the Chinese Academy of Sciences (XDB15030302), National Basic Research Program of China (973 Program) (2012CB416905), and National Natural Science Foundation of China (31200479, 31570620). A grant from US National Science Foundation (Grant No. 1354659) supported Cheng's work. 


\section{References}

Bader, N.E., Cheng, W.X., 2007. Rhizosphere priming effect of Populus fremontii obscures the temperature sensitivity of soil organic carbon respiration. Soil Biology and Biochemistry 39, 600-606.

Bernal, B., McKinley, D.C., Hungate, B.A., White, P.M., Mozdzer, T.J., Megonigal, J.P., 2016. Limits to soil carbon stability: Deep, ancient soil carbon decomposition stimulated by new labile organic inputs. Soil Biology and Biochemistry 98, 85-94.

Bingemann, C.W., Varner, J.E., Martin, W.P., 1953. The effect ofthe addition of organic materials on the decomposition of an organic soil. Soil Science Society of America Proceedings 17, $34-38$.

Bird, J.A., Herman, D.J., Firestone, M.K., 2011.Rhizosphere priming of soil organic matter by bacterial groups in a grassland soil. Soil Biology and Biochemistry 43, 718-725.

Brzostek, E.R., Dragoni, D., Brown, Z.A., Phillips, R.P., 2015. Mycorrhizal type determines the magnitude and direction of root-induced changes in decomposition in a temperate forest. New Phytologist 206, 1274-1282.

Cheng, W.X., 2009. Rhizosphere priming effect: its functional relationships with microbial turnover, evapotranspiration, and C-N budgets. Soil Biology and Biochemistry 41, 1795-1801.

Cheng, W.X., Johnson, D.W., Fu, S., 2003. Rhizosphere effects on decomposition: controls of plant species, phenology, and fertilization. Soil Science Society of America Journal 67, 1418-1427.

Cheng, W.X., Parton, W.J., Gonzalez-Meler, M.A., Phillips, R., Asao, S., McNickle, G., Brzostek, E., Jastrow, J., 2014. Synthesis and modeling perspectives of rhizosphere priming. New Phytologist 201, 31-44.

Creamer, C.A., Jones, D.L., Baldock, J.A., Rui, Y.C., Murphy, D.V., Hoyle, F.C., Farrell, M., 2016. Is the fate of glucose-derived carbon more strongly driven by nutrient availability, soil texture, 
or microbial biomass size? Soil Biology and Biochemistry 103, 201-212.

Dijkstra, F.A., Cheng, W.X., 2007. Interactions between soil and tree roots accelerate long-term soil carbon decomposition. Ecology Letters 10, 1046-1053.

Dijkstra, F.A., Carrillo, Y., Pendall, E., Morgan, J.A., 2013. Rhizosphere priming: a nutrient perspective. Frontiers in Microbiology 4, 1-8.

Dijkstra, F.A., Cheng, W.X., Johnson, D.W., 2006. Plant biomass influences rhizosphere priming effects on soil organic matter decomposition in two differently managed soils. Soil Biology and Biochemistry 38, 2519-2526.

Dijkstra, F.A., Morgan, J.A., Blumenthal, D., Follett, R.F., 2010. Water limitation and plant inter-specific competition reduce rhizosphere induced C decomposition and plant $\mathrm{N}$ uptake. Soil Biology and Biochemistry 42, 1073-1082.

Drake, J.E., Gallet-Budynek, A., Hofmockel, K.S., Bernhardt, E.S., Billings, S.A., Jackson, R.B., Johnsen, K.S., Lichter, J., McCarthy, H.R., McCormack, M.L., Moore, D.J. P., Oren, R., Palmroth, S., Phillips, R.P., Pippen, J.S., Pritchard, S.G., Treseder, K.K., Schlesinger, W.H., DeLucia1, E.H., Finzi, A.C., 2011. Increases in the flux of carbon belowground stimulate nitrogen uptake and sustain the long-term enhancement of forest productivity under elevated $\mathrm{CO}_{2}$. Ecology Letters 14, 349-357.

Finzi, A.C., Abramoff, R.Z., Spiller, K.S., Brzostek, E.R., Darby, B.A., Kramer, M.A., Phillips, R.P., 2015. Rhizosphere processes are quantitatively important components of terrestrial carbon and nutrient cycles. Global Change Biology 21, 2082-2094.

Fontaine, S., Barot, S., Barre, P., Bdioui, N., Mary, B., Rumpel, C., 2007. Stability of organic carbon in deep soil layers controlled by fresh carbon supply. Nature 450, 277-280.

Gurevitch, J., Curtis, P.S., Jones, M.H., 2001. Meta-analysis in ecology. Advances in Ecological Research 32, 199-247.

Haichar, F., Santaella, C., Heulin, T., Achouak, W., 2014. Root exudates mediated interactions 
belowground. Soil Biology and Biochemistry 77, 69-80.

Hedges, L.V., Gurevitch, J., Curtis, P.S., 1999. The meta-analysis of response ratios in experimental ecology. Ecology 80, 1150-1156.

Herman, D.J., Johnson, K.K., Jeger, C.H., Schwartz, E., Firestone, M.K., 2006. Root influence on N mineralization and nitrification in Avena barbata rhizosphere soil. Soil Science Society of America Journal 70, 1504-1511.

Hoosbeek, M.R., Li, Y.T., Scarascia-Mugnozza, G.E., 2006. Free atmospheric $\mathrm{CO}_{2}$ enrichment (FACE) increased labile and total carbon in the mineral soil of a short rotation Poplar plantation. Plant and Soil 281, 247-254.

Keiluweit, M., Bougoure, J.J., Nico, P.S., Pett-Ridge, J., Weber, P.K., Kleber, M., 2015. Mineral protection of soil carbon counteracted by root exudates. Nature Climate Change 5, 588-595. Keith, A., Singh, B., Dijkstra, F.A., 2015. Biochar reduces the rhizosphere priming effect on soil organic carbon. Soil Biology and Biochemistry 88, 372-379.

Kumar, A., Kuzyakov, Y., Pausch, P., 2016. Maize rhizosphere priming: field estimates using ${ }^{13} \mathrm{C}$ natural abundance. Plant and Soil 409, 87-97.

Kuzyakov, Y., 2002. Review: factors affecting rhizosphere priming effects. Journal of Plant Nutrition and Soil Science 165, 382-396.

Kuzyakov, Y., 2010. Priming effects: interactions between living and dead organic matter. Soil Biology and Biochemistry 42, 1363-1371.

Kuzyakov, Y., Blagodatskaya, E., 2015. Microbial hotspots and hot moments in soil: concept and review. Soil Biology and Biochemistry 83, 184-199.

Kuzyakov, Y., Cheng, W.X., 2001. Photosynthesis controls of rhizosphere respiration and organic matter decomposition. Soil Biology and Biochemistry 33, 1915-1925.

Kuzyakov, Y., Cheng, W.X., 2004. Photosynthesis controls of $\mathrm{CO}_{2}$ efflux from maize rhizosphere. Plant and Soil 263, 85-99. 
Kuzyakov, Y., Xu, X., 2013. Competition between roots and microorganisms for nitrogen: mechanisms and ecological relevance. New Phytologist 198, 656-69.

Kuzyakov, Y., Friedel, J.K., Stahr, K., 2000. Review of mechanisms and quantification of priming effects. Soil Biology and Biochemistry 32, 1485-1498.

Kuzyakov, Y., Subbotina, I., Chen, H., Bogomolova, I., Xu, X., 2009. Black carbon decomposition and incorporation into soil microbial biomass estimated by ${ }^{14} \mathrm{C}$ labeling. Soil Biology and Biochemistry 41, 210-219.

Liao, C., Peng, R., Luo, Y., Zhou, X., Wu, X., Fang, C., Chen, J., Li, B., 2008. Altered ecosystem carbon and nitrogen cycles by plant invasion: a meta-analysis. New Phytologist 177, 706-14.

Liljeroth, E., Kuikman, P., Van Veen, J.A., 1994. Carbon translocation to the rhizosphere of maize and wheat and influence on the turnover of native soil organic matter at different soil nitrogen levels. Plant and Soil 161, 233-240.

Linkosalmi, M., Pumpanen, J., Biasi, C., Heinonsalo, J., Laiho, R., Lindén, A., Palonen, V.,Laurila, T., Lohila, A., 2015. Studying the impact of living roots on the decomposition of soil organic matter in two different forestry-drained peatlands. Plant and Soil 396, 59-72.

Liu, X.A., Sun, J., Mau, R.L., Finley, B.K., Compson, Z.G., van Gestel, N., Brown, J.R., Schwartz, E., Dijkstra, P., Hungate, B.A., 2017. Labile carbon input determines the direction and magnitude of the priming effect. Applied Soil Ecology 109, 7-13.

Löhnis, F., 1926. Nitrogen availability of green manures. Soil Science 22, 253-290.

Luo, Z., Wang, E., Smith, C.J., 2015. Fresh carbon input differentially impacts soil carbon decomposition across natural and managed systems. Ecology 96, 2806-2813.

Luo, Z.K., Wang, E.L., Sun, O.J., 2016. A meta-analysis of the temporal dynamics of priming soil carbon decomposition by fresh carbon inputs across ecosystems. Soil Biology and Biochemistry 101, 96-103.

Mwafulirwa, L., Baggs, E.M., Russell, J., George, T., Morley, N., Sim, A., Cantó, C., Paterson, E., 
2016. Barley genotype influences stabilization of rhizodeposition-derived C and soil organic matter mineralization. Soil Biology and Biochemistry 95, 60-69.

Mueller, P., Jensen, K., Megonigal, J.P., 2016. Plants mediate soil organic matter decomposition in response to sea level rise. Global Change Biology 22, 404-414.

Phillips, R.P., Fahey, T.J., 2006. Tree species and mycorrhizal associations influence the magnitude of rhizosphere effects. Ecology 87, 1302-1313.

Phillips, R.P., Meier, I.C., Bernhardt, E.S., Grandy, A.S., Wickings, K., Finzi, A.C., 2012. Roots and fungi accelerate carbon and nitrogen cycling in forests exposed to elevated $\mathrm{CO}_{2}$. Ecology Letters $15,1042-1049$.

Qiao, N., Schaefer, D., Blagodatskaya, E., Zou, X.M., Xu, X.L., Kuzyakov, Y., 2014. Labile-carbon retention compensates for $\mathrm{CO}_{2}$ released by priming in forest soils. Global Change Biology 20, $1943-1954$.

Rosenberg, M., Adams, D., Gurevitch, J., 2000. MetaWin: Statistical software for meta-analysis. Sunderland, MA, USA: Sinauer Associates.

Rousk, J., Hill, P.W., Jones, D.L., 2015. Priming of the decomposition of ageing soil organic matter: concentration dependence and microbial control. Functional Ecology 29, 285-296.

Shahzad, T., Chenu, C., Genet, P., Barot, S., Perveen, N., Mougin, C., Fontaine, S., 2015.

Contribution of exudates, arbuscular mycorrhizal fungi and litter depositions to the rhizosphere priming effect induced by grassland species. Soil Biology and Biochemistry 80, 146-155.

Shahzad, T., Chenu, C., Repinçay, C., Mougin, C., Ollier, J.-L., Fontaine, S., 2012. Plant clipping decelerates the mineralization of recalcitrant soil organic matter under multiple grassland species. Soil Biology and Biochemistry 51, 73-80.

Sinyakina, S.V., Kuzyakov, Y., 2002. The ${ }^{14} \mathrm{C}$ tracer study of carbon turnover in soil in a model experiment. Eurasian Soil Science 35, 1287-1295.

Spohn, M., Klaus, K., Wanek, W., Richter, A., 2016a. Microbial carbon use efficiency and biomass 
turnover times depending on soil depth - Implications for carbon cycling. Soil Biology and Biochemistry 96, 74-81.

Spohn, M., Pötsch, E.M., Eichorst, S.A., Woebken, D., Wanek, W., Richter, A., 2016b. Soil microbial carbon use efficiency and biomass turnover in a long-term fertilization experiment in a temperate grassland. Soil Biology and Biochemistry 97, 168-175.

Thurgood, A., Singh, B., Jones, E., Barbour, M.M., 2014. Temperature sensitivity of soil and root respiration in contrasting soils. Plant and Soil 382, 253-267.

Van Groenigen, K.J., Qi, X., Osenberg, C.W., Luo, Y.Q., Hungate, B.A., 2014. Faster decomposition under increased atmospheric $\mathrm{CO}_{2}$ limits soil carbon storage. Science 344, 508-509.

Vestergärd, M., Reinsch, S., Bengtson, P., Ambus, P., Christensen, S., 2016. Enhanced priming of old, not new soil carbon at elevated atmospheric $\mathrm{CO}_{2}$. Soil Biology and Biochemistry 100, $140-148$.

Wang, H., Boutton, Thomas, W., Xu, W.H., Hu, G.Q., Jiang, P., Bai, E., 2015. Quality of fresh organic matter affects priming of soil organic matter and substrate utilization patterns of microbes. Scientific Reports 5, 10102; doi: 10.1038/srep10102

Wang, X.J., Tang, C.X., Severi, J., Butterly, C.R., Baldock, J.A., 2016. Rhizosphere priming effect on soil organic carbon decomposition under plant species differing in soil acidification and root exudation. New Phytologist 211, 864-873.

Wolf, A.A., Drake, B.G., Erickson, J.E., Megonigal, J.P., 2007. An oxygen-mediated positive feedback between elevated carbon dioxide and soil organic matter decomposition in a simulated anaerobic wetland. Global Change Biology 13, 2036-2044.

Zhang, W., Wang, X., Wang, S., 2013. Addition of external organic carbon and native soil organic carbon decomposition: a meta-analysis. PLoS ONE 8, e54779.doi10.1371.

Zhu, B., Cheng, W.X., 2011. Rhizosphere priming effect increases the temperature sensitivity of soil organic matter decomposition. Global Change Biology 17, 2172-2183. 
Zhu, B., Cheng, W.X., 2013. Impacts of drying-wetting cycles on rhizosphere respiration and soil organic matter decomposition. Soil Biology and Biochemistry 63, 89-96. 


\section{Supporting Information}

Additional supporting information may be found in the online version of this article.

Table S1 List of all references used in the meta-analysis

Table S2 Data used in the meta-analysis

Figure S1 Scatter plots between the rhizosphere priming effect (RPE) and soil variables 


\section{Figure legends}

Figure 1. Effect sizes of the rhizosphere priming effect (mean $\pm 95 \%$ CI, CI is confidence interval) categorized by plant types (Woody, Grassland species, Crops and Others) and soil texture (Fine, and Coarse). The sample sizes for each group were given on the left $y$-axis. The dashed line was drawn at mean effect size $=0$. The treatment effect (rhizosphere priming) is statistically significant if the $95 \%$ CI of the effect size does not overlap with the zero line.

Figure 2. Scatter plots and linear correlations (the solid line) between the rhizosphere priming effect (RPE) and plant and soil variables. Line is the best-fit regression. Each symbol represents one observation. RPE values from repeated measures through time within one study were not aggregated for the plot between RPE values and plant biomass and for the plot between RPE and day after planting. Repeated measures were aggregated by averaging for the plot between RPE and soil microbial biomass carbon. The RPE increased significantly with plant total biomass $\left(n=113, R^{2}=\right.$ $0.077, P<0.003)$, aboveground biomass $\left(\mathrm{n}=113, \mathrm{R}^{2}=0.119, P<0.001\right)$, days after planting $(\mathrm{n}=$ $\left.190, \mathrm{R}^{2}=0.228, P<0.001\right)$ and soil microbial biomass carbon $\left(\mathrm{n}=39, \mathrm{R}^{2}=0.103, P<0.05\right)$. The RPE was not significantly related to plant root biomass. RPE $=\left(X_{\mathrm{t}} / X_{\mathrm{c}}-1\right) \times 100$, where $X_{t}$ and $X_{c}$ are the means (SOM derived $\mathrm{CO}_{2}$ efflux rate) of the planted soil and the unplanted control soil under the same soil and environmental conditions, respectively. 
Table 1 Relationships between the effect size (ln RR) of the RPE and plant and soil variables by two analyzing methods. "n" in the header is the number of data points; $P$-values with (-) indicate negative correlation. $P$-values in bold are statistically significant at the $P<0.05$ or $P<0.001$ level.

\begin{tabular}{lllllllc}
\hline Variables & & \multicolumn{4}{c}{ Random effect model $^{\#}$} & \multicolumn{2}{c}{ Linear correlation* $^{*}$} \\
\cline { 2 - 8 } & $\mathbf{n}$ & $\mathbf{Q}_{\mathbf{T}}$ & $\mathbf{Q}_{\mathbf{M}}$ & $\mathbf{Q}_{\mathbf{E}}$ & $\boldsymbol{P}$-value & $\mathbf{R}^{\mathbf{2}}$ & $\boldsymbol{P}$-value \\
\hline Plant total biomass & 113 & 170.88 & 13.46 & 157.42 & $\mathbf{0 . 0 0 0}$ & 0.077 & $\mathbf{0 . 0 0 3}$ \\
Plant shoot biomass & 113 & 175.35 & 21.26 & 154.09 & $\mathbf{0 . 0 0 0}$ & 0.119 & $<\mathbf{0 . 0 0 1}$ \\
Plant root biomass & 113 & 147.40 & 0.01 & 147.39 & -0.911 & 0.000 & -0.915 \\
Days after planting & 190 & 317.37 & 73.00 & 244.37 & $\mathbf{0 . 0 0 0}$ & 0.228 & $<\mathbf{0 . 0 0 1}$ \\
Soil organic C & 53 & 55.95 & 0.01 & 55.94 & -0.965 & 0.000 & -0.927 \\
Soil total N & 53 & 54.89 & 0.10 & 54.80 & -0.755 & 0.007 & -0.537 \\
C:N ratio & 53 & 55.82 & 0.21 & 55.61 & 0.654 & 0.004 & 0.664 \\
pH & 65 & 86.98 & 1.64 & 85.34 & 0.201 & 0.014 & 0.355 \\
Microbial biomass C & 39 & 51.97 & 5.17 & 46.81 & $\mathbf{0 . 0 2 3}$ & 0.103 & $\mathbf{0 . 0 4 6}$ \\
\hline
\end{tabular}

${ }^{\#}$ Testing for relationships between $\ln (\mathrm{RR})$ and plant and soil variables by continuous random effect model with MetaWin. Statistical results were reported as total heterogeneity in effect sizes among all observations $\left(\mathrm{Q}_{\mathrm{T}}\right)$, the difference among group cumulative effect sizes $\left(\mathrm{Q}_{\mathrm{M}}\right)$, and the residual error $\left(\mathrm{Q}_{\mathrm{E}}\right)$ from continuous randomized-effects model meta-analyses. The relationship is significant when $P<0.05 . \boldsymbol{n}$ is the number of observations. Values from repeated measures through time were not aggregated by averaging for the relationships between $\ln (\mathrm{RR})$ and plant biomass variables and between $\ln (\mathrm{RR})$ and DAP (day after planting).

${ }^{*}$ Linear correlations between $\ln (\mathrm{RR})$ and plant and soil variables (using SPSS software). $P$-values with (-) indicate negative correlation. 
Figure 1

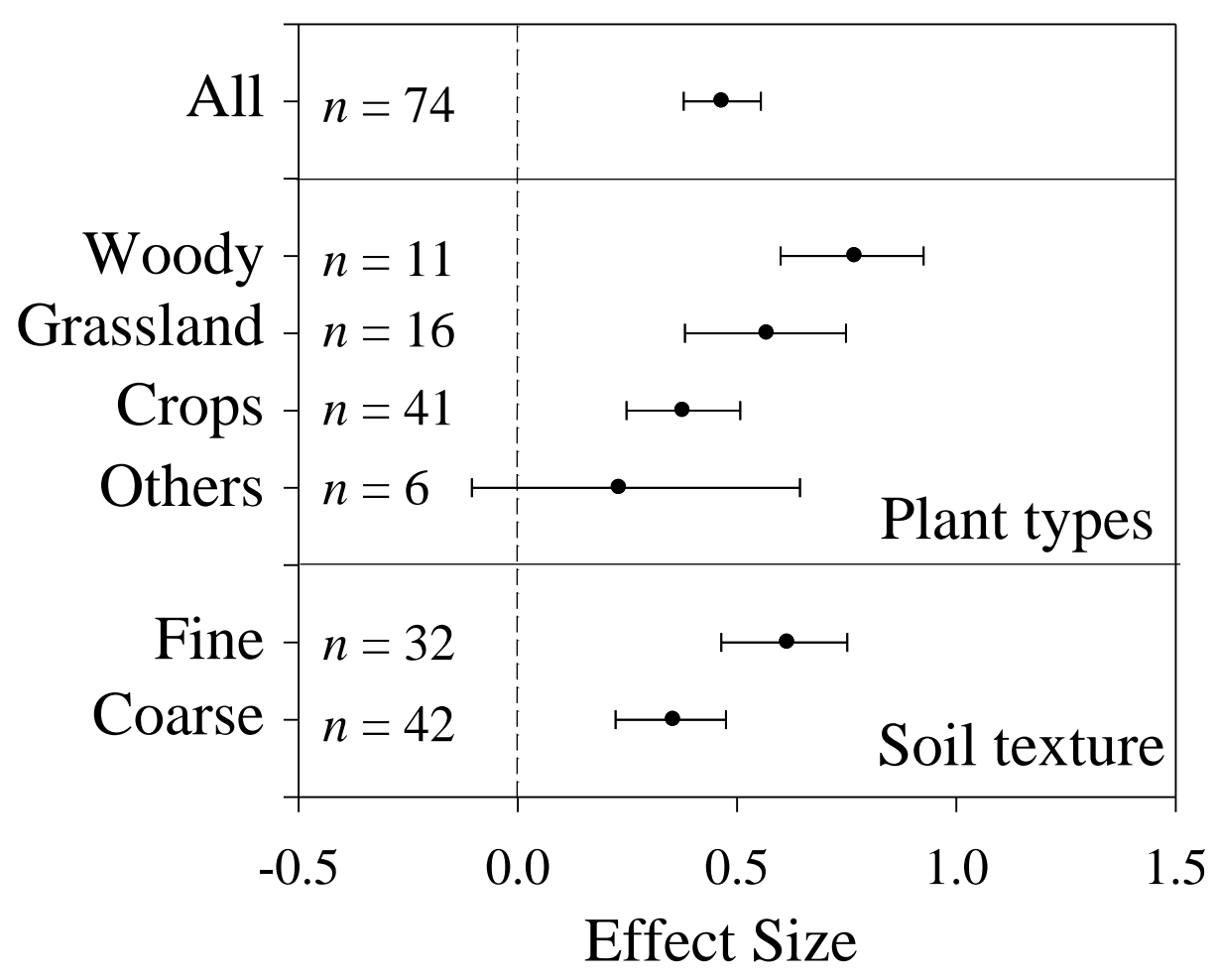


Figure 2
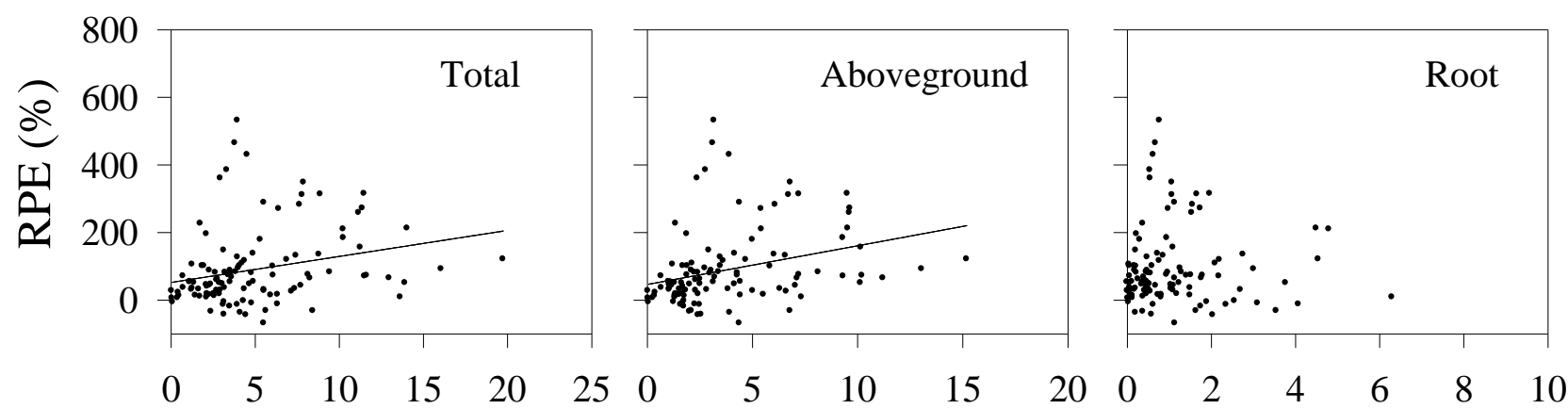

Plant biomass ( $\mathrm{g} \mathrm{kg}^{-1}$ soil)

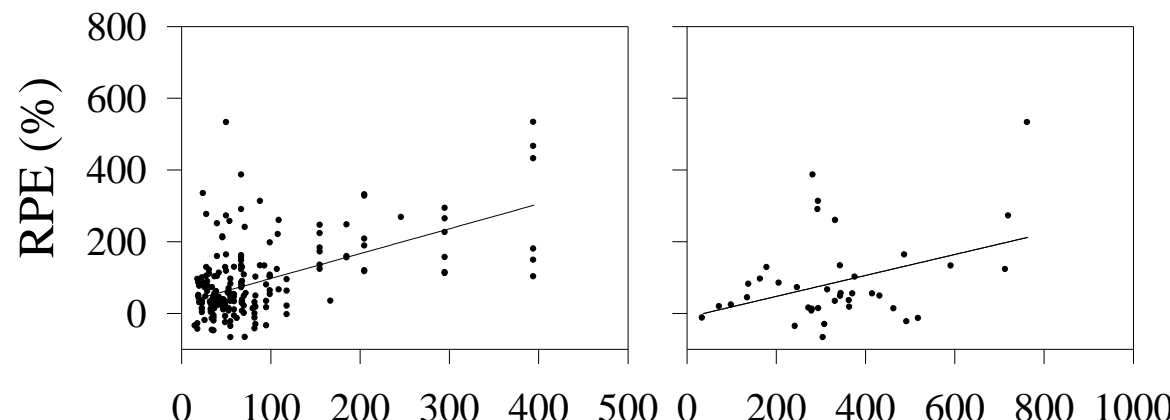

Days after planting (day) Microbial biomass ( $\mathrm{mg} \mathrm{C} \mathrm{kg}^{-1}$ soil) 